\title{
From passive listeners to active participants
} Lessons learned from the pandemic about engaging international students during library instruction

The 2020-21 academic year was a time of challenges, innovation, and transformation for many library services, library instruction included. Many academic libraries sought to transition lesson plans to synchronous and asynchronous online formats. Some students left to travel back home, whether that was in state, out of state, or out of the country. These challenges not only perplexed individual instructors, but also complicated library instruction plans. Though many universities have now resumed pre-pandemic services and activities, we should continue to reflect on what worked well during the pandemic that we can continue to incorporate as we move into more normalized times.

\section{Library instruction practices and international students}

Teaching librarians engage in evidence-based pedagogies, such as backward design and active learning strategies, to engage students. These practices spur students to apply what's being taught in a dynamic environment where it's safe to make mistakes. However, not all students respond the same way to pedagogies commonly used in Western educational systems. ${ }^{1}$ International students experience different student learning practices. In east Asia, it's common for students to be accustomed to individual work, an all-authoritative teacher, ten-hour school days, and high-stakes exams. Students may not be used to group work, sharing opinions in class, or asking questions. ${ }^{2}$ This adds a layer of complexity when planning lessons designed for international students.

Penn State-Harrisburg is Penn State's largest commonwealth campus and has a thriving international student population. More than 600 students, roughly 12\% of the student population, are international. Students who identify as English Language Learners (ELL) may choose to enroll in a first-year two-course sequence, which together fulfill their first-year composition course credits. In the fall, students take First-Year Seminar in English (ENGL 83S). During library instruction, students receive a library orientation that covers how the university libraries operates, Harrisburg Library as their campus library, how librarians can help them, and how to find basic information on the library website. In the spring, students take ESL Composition for American Academic Communication II (ESL 15). In this course, students learn how to begin researching using library resources. Traditionally, students in these courses received library lessons via in-person instruction from a librarian.

Emily Reed is reference and instruction librarian at the Penn State University Libraries, email: emilyreed@psu.edu 


\section{Pandemic-related challenges}

Travel restrictions

As many universities opted to deliver course content remotely during 2020-21, library instruction likewise had to transition. International students had additional challenges to navigate. Many universities, Penn State included, required courses to run synchronously. Since some students were unable to travel to their college destinations due to travel restrictions, they had to remain in their home countries. At Penn State-Harrisburg, many international students come from China, followed by India, Korea, Saudi Arabia, Malaysia, the UAE, and Taiwan. ${ }^{3}$ These students were required to attend classes during their scheduled meeting times and had to contend with a significant time difference.

\section{Differing classroom cultures}

Additionally, students and librarians had to navigate differing instructor policies, guidelines, teaching practices, and classroom cultures. Some course instructors were able to establish a rigorous classroom environment with required student participation, requiring students to participate in the chat window, break out into small groups for discussion, complete worksheets during class, etc. Student participation required effort and was visible. Other course instructors lectured from a prepared set of slides to a screen of students who were represented by black Zoom windows displaying only their name with no student engagement. Students attending these types of classes were able to retreat into the background, finding comfort in nonparticipation and not having to be seen or heard while the instructor chattered into the void.

\section{Participation and engagement}

For librarians who primarily teach via the synchronous one-shot format, these differences were exacerbated due to the transition to online learning. Librarians worked to adapt lesson plans for an online environment that taught students how to think about research, locate information, evaluate sources, and teach other information literacy concepts. It was a risk to develop learning activities that required student participation when there was no guarantee that virtual lesson activities would match the classroom culture already established by the course instructor. Many librarians experienced at least one class where it was clear that the classroom culture of nonparticipation had already been firmly established--students would not respond in chat (well, maybe one or two brave souls would), ask questions, or participate in discussions. In these classes, students were comfortable not participating. To be asked by the guest speaker to think, type in the chat, or contribute to a collaborative document was a new concept. This meant giving up privacy, taking the risk of being wrong, and getting called out. When students don't participate, formative assessment is an impossible task.

The culture of nonparticipation was seemingly encouraged by requiring students still living overseas to participate synchronously. Many course instructors empathetically wanted to remain flexible with their students. They understood that it was the middle of the night when some of their students were required to attend class. When it's the wee hours of the morning, who wants their camera on? Who's ready to fully engage in a thought-provoking discussion? Many students were living at home with their families, with family members trying to sleep in other rooms or even the same room. 
While librarians may want to try to accommodate every student learning challenge, we simply cannot due to many constraints. It's necessary to pick and choose which challenges we are most equipped to address. There are some strategies that can mediate some of these concerns to encourage more student engagement.

\section{Response}

Allowing for semi-anonymity

In 2020-21, I adapted my lesson plans for the ELL first-year composition courses from an in-person mode to an online synchronous format. Realizing the challenges that online distance international students face, I wanted to encourage participation during the lesson to gather and respond to formative assessment, while respecting that students may not be used to regular participation. My solution was to present the lesson using a technology in which student participation was built directly into the synchronous lesson while maintaining semi-anonymity. I used Nearpod, a freemium educational platform that allows an instructor to cast slides to a student's personal device. ${ }^{4}$ Slides can contain a mix of static informational content such as a slide deck, dynamic content such as websites where the students can navigate the site on their own, and activities to be used as checkpoints such as multiple-choice quiz questions, poll questions, open-ended questions, and more.

One concern when preparing an interactive lesson is that sometimes international students are hesitant to speak up because they do not want to be "wrong," even when there isn't a wrong answer to the question posed. Many students feel a sense of shame when they are called out for being wrong, and this causes them to prefer to stay silent rather than participate or ask questions when they don't understand something. This concern can be largely mitigated by taking advantage of platforms that allow for anonymous or semi-anonymous participation. At the start of my lesson, I provided directions to the students to join the Nearpod lesson and explained what types of activities the lesson would entail. I emphasized that student participation would be anonymous to the other students in the class and on the recording but would be identifiable by myself and the course instructor. This semi-anonymous setting keeps students accountable for their participation, but more willing to participate because they do not fear being wrong in front of their peers.

\section{Participative learning activities}

I taught two different lesson plans using Nearpod. In the fall ENGL $83 \mathrm{~S}$ course, I taught students about library services, introduced them to the subject librarians, gave an overview of the library website, and explained library policies. I developed interactive activities throughout the lesson to stimulate thinking about the library, such as polling for students' prior experiences with libraries, knowledge checkpoints to make sure they were following along and understanding the lesson content, and had students interact with selected pages of the library website.

In the spring, the ESL 15 lesson plan entailed learning about how to begin research, how to use library resources to locate information, and how to evaluate sources. Interactive student activities included having students identify a topic of interest in response to an open-ended question, knowledge checks, and listing keywords for a pre-selected topic by using a "collaborate board," similar to a Padlet. ${ }^{5}$ 


\section{Risks}

There are inherent risks to a librarian using a technology like Nearpod during a one-shot. Using these types of interactive tools require students to adapt quickly to a new technology tool they may have never used before. There may be technical difficulties making the lesson start delayed, losing valuable teaching time. Some technology tools are geo-blocked by certain countries. It also requires that the students have a stable Internet connection with enough bandwidth to accommodate the learning technology as well as the course's videoconferencing software. And not all educational technologies are accessible for students with disabilities. There could also be relational ramifications if the course instructor is not supportive of the librarian introducing their students to a new tool, which may disrupt the classroom norm.

\section{Student response}

In the spring, I ended the Nearpod lesson by asking students to respond to a multiplechoice question, "Did you like using Nearpod during this lesson?" Out of 82 students, this question received an $82 \%$ response rate: $80 \%$ of students who responded selected "yes," $14 \%$ said they "didn't particularly like or dislike Nearpod," and 6\% selected "no." These informal survey responses indicate that most students had a positive learning experience using Nearpod, and only a few did not.

\section{Moving forward}

In fall 2021, many of our international students returned to my campus to attend classes in person. However, many other universities are continuing to offer certain courses asynchronously, synchronously online, or in a hybrid format. There is still a need for teaching librarians to remain flexible with teaching modality changes and for us to reflect on what teaching practices improved the learning experiences of our students during the pandemic. Some tools can make teaching hybrid or online classes more engaging. Nearpod is capable of reaching both in-person and online students, so it works well in both a synchronous online and a hybrid situation. It also has an option to make a lesson asynchronous so that students can go through a lesson at their own pace on their own time.

This fall, I have continued to use Nearpod for my in-person classes. I am currently avoiding classroom activities that put students in close proximity to each other, involve the exchange of papers or other materials, and activities that are made more difficult because of masks, such as lengthy discussions. So, I am continuing to encourage individual participation during class rather than group work. International students, in particular, seem to participate more fully because their engagement is anonymous to their peers, so Nearpod has been successful for me in getting informal formative assessment, which allows me to respond in real time to confusion and questions.

Some considerations when thinking about piloting or adopting a student learning technology include:

1. Is it accessible for students with disabilities?

2. Will it reach students who may be overseas, or is it geo-blocked?

3. What is the privacy policy of the vendor?

4. Is it free? Is there a storage limit or student limit? 
It's also important to compare alternative tools. Some of Nearpod's competitors include LibWizard $^{6}$ and TopHat. ${ }^{7}$ There are also various tools that allow a user to incorporate questions during a video, such as Kaltura. ${ }^{8}$ Educational technology seems to always live in a state of corporate flux, being bought out by larger companies who may decide to make them unavailable. Teaching librarians will need to continue to remain flexible and not rely on one sole vendor to provide a platform for lessons.

While teaching international students can present some interesting challenges to teaching librarians, it also invites an opportunity to expose students to new learner-centered techniques. They may not be comfortable at first with the expectation for participation, but with time, they can adapt and hopefully come to appreciate the pedagogies they experience as they learn to engage in discourse, ask questions, and form collegial bonds with other students during discussion and group work.

\section{Notes}

1. Haijun Kang and Bo Chang, "Examining Culture's Impact on the Learning Behaviors of International Students from Confucius Culture Studying in Western Online Learning Context," Journal of International Students 6, no. 3 (Jul): 779-797, https://doi.org/10.32674/ jis.v6i3.356.

2. Richard Mast, "How Culture Affects How Chinese Students Approach Learning in Western Education Environments," The International Schools Journal 36, no. 1 (11): 40-47.

3. Office of International Student Support Services, "International Students at Penn State Harrisburg as of Fall, 2020."

4. "How Nearpod Works," https://nearpod.com/how-nearpod-works (accessed June 2, 2021).

5. "Everything You Need, Nothing You Don't," https://padlet.com/features (accessed June $14,2021)$.

6. "Libwizard," https://www.springshare.com/libwizard/ (accessed June 2, 2021).

7. "Let's Make Education Better," https://tophat.com/company/top-hat-story/ (accessed June 2, 2021).

8. "Everything Video," https://corp.kaltura.com/company/about/ (accessed June 2, 2021). $ぇ$ 